\title{
One Must Go Quickly from One Light into Another: Between Ingeborg Bachmann and Jacques Derrida
}

\begin{abstract}
SABINE I. GÖLZ
We here enter a textual labyrinth panelled with mirrors.

-Jacques Derrida

I am the thought on the bath in the room without mirrors.

—Nadja, as "cited" by André Breton
\end{abstract}

We have grown used to asserting that "language" somehow contributes to marginalizing some people and centering others. These effects have especially interested feminist critics and theorists working with marginalized ethnic, racial, and colonized groups. Yet the process remains opaque. How can signifying processes make a given symbolic, metaphoric, or linguistic order more habitable to some than to others? To address these issues, let us start with the notion that representational practices are also what makes constructions of knowledge and subjecthood possible in a given symbolic order. Through them we shape ourselves and our world.

To explore these dynamics we must find ways to orient ourselves in the twilight zone of the interference between representations and the practices with which we surround them. Any power of and over representation and the constitution of a "world" derives from the decisions made in that undecidable space. Comparative methodology is indispensable for orientation in this twilight because it allows us to approach this space not in terms of the metaphysical opposition between the original and the copy, the real and the image, but rather by means of a comparison between the various effects that arise out of their interference.

I set the stage here by reading one stanza from a long poem by the Austrian poet Ingeborg Bachmann. The central section of the essay then presents a detailed reading of the first part of Jacques Derrida's essay 
"The Double Session,"1 where I locate the stance of Derridean deconstruction on the map provided by Bachmann's poem. Deconstruction's practices and choices situate it on a site different from that of Bachmann. The comparison gives relief to the "large trace" of a significant difference between the stances of these two writers. This difference becomes even clearer when, by way of conclusion, I look at two moments when each of these writers interacts with another text through citation. This adds the dimension of readerly practice to my considerations. We end up with a quadruple scene of supplementation and differing which allows us to map divergences between the two stances unperceived by the deconstructive "double scene."

Ingeborg Bachmann calls for a comparative method of mapping one's world:

In a time of large traces,
one must go quickly from one light
into another, from one land
into another, under the rainbow,
the compass point in the heart,
the night taken as radius.
Wide open.

She thus directly addresses the question that interests all of us in this volume. Her poem further links the necessity for comparison to our "large-traced" or "overbearing" (großspurige) time. She is concerned with the conditions under which the "large" trace of a whole signifying apparatus, a predominant practice, can be observed. Central to this ef-

"Jacques Derrida, "The Double Session," in Dissemination, trans. Barbara Johnson (Chicago: University of Chicago Press, 1981), 173-286 (hereafter DS).

${ }^{2}$ "In einer großspurigen Zeit / muß man rasch von einem Licht / ins andre gehen, von einem Land / ins andre, unterm Regenbogen, / dieZirkelspitze im Herzen, / zum Radius genommen die Nacht. / Weit offen." Ingeborg Bachmann, "Curriculum Vitae," in Werke, ed. Christine Koschel, Inge von Weidenbaum, and Clemens Münster (Munich: Piper, 1982), 1:101 (hereafter IBW). This poem is quoted with the kind permission of Piper Verlag, (c) R. Piper and Co. Verlag, Munich, 1978. The translation is my own. Mark Anderson translates these lines from the sixth stanza: "In an arrogant age / we must rush from one light / to the next, from one land / into the next, beneath the rainbow, / the compass points in our heart / and the night as radius. / Wide open." In the Storm of Roses: Selected Poems by Ingeborg Bachmann, trans. Mark Anderson (Princeton: Princeton University Press, 1986), 97. He thus chooses the common meaning of the German großspurig ("arrogant") over the more etymological meaning. The choice of the word "rush" and the multiplication of compass "points" to my mind lose the measured precision of this line, which corresponds to its geometric metaphorics. Since translations reflect such differences in interpretation, I will be using my own throughout. 
fort is the comparative movement across the boundaries delimiting different perspectives and discursive spaces, different lights and lands.

The poem maintains awareness of the observer's irreducible part in constituting the object of observation. It approaches its task not by constructing the "large-traced time" as an object, but by describing procedures for observing it. The only fixed point of the procedure is a compass point placed "in the heart." The gesture piercingly anchors the radius of perception in the observer. The goal of the process, finally, is not comprehensiveness but the production of an opening as "wide" and unlimited as the initial movement was pointed. That opening, however, depends on the poignant precision of the initial gesture.

Only after the procedure has been established can we say what we see: "From the mountains / one sees lakes, in the lakes / mountains (Von den Bergen / sieht man Seen, in den Seen / Berge)." At first glance this chiastic arrangement seems to create a reciprocal relation in which the knowers and the known change places and their difference becomes undecidable. Yet this reciprocity is subtly compromised. Whereas the mountains are a location from which either the lakes or their own reflection in the lakes may be seen, the lakes either reflect or are seen but are never the site of seeing. As the lakes appear and disappear, now object, now mirror, the mountains remain invested with the gaze.

The appearance of complementarity is replaced by a scenario of exclusion as we look (move?) elsewhere: "and in the rack of cloud / swing the bells / of the one world. Whose world / I am forbidden to know (und im Wolkengestühl / schaukeln die Glocken / der einen Welt. Wessen Welt / zu wissen ist mir verboten)." We see "the one" world, somebody's world. "One" denotes unification but also has the opposite effect of evoking the shadowy, unnamed possibility of "other" worlds. This reading gains force as the first-person pronoun emerges in the very recognition of its exclusion from knowledge, and as it points to an acoustic dimension ("bells") to which the specular scenario is deaf. If this "I" inhabits a world different from the "one," this world remains unrepresented. We can imagine that the "lakes" where the mountains reassure themselves alternately of their own image and of the objects of their knowledge are inhabited by a gaze which knows itself as forbidden. But the difference of this gaze will appear exclusively in what it sees and hears. Therefore, we will not find it unless we make it our own and begin to see or hear differently ourselves.

The lyrical "I" of Bachmann's poem could be said to position itself in the mirror of representation as what Lacan calls the object $a$. According to Mladen Dolar, the object $a$ "is precisely that part of the loss 
that one cannot see in the mirror, the part of the subject that has no mirror reflection, the nonspecular." Lost is the gaze that looks back at the Lacanian subject, as it situates itself on the mountain, founded on both its difference from and self-recognition in a mirror image. That otherworldly gaze out of the lake appears to "the one" subject as uncanny, horrifying and "impossible." ${ }^{3}$

The specular subject and its faith in imaginary unity can be maintained only if the reverse gaze from the mirror remains "lost." But were we to position ourselves (as Bachmann invites us to do) as that missing second gaze, we would begin to perceive a split that is far greater than the founding split between that subject and his mirror image. The missing gaze would appear neither as part of that subject nor as part of his world, but as the gaze of a different kind of subject. This subject, as which we can situate ourselves, must as a founding condition of its existence lose faith in representation, in any image of itself. In order to constitute itself as a subject at all, it must depart from a symbolic space in which it was represented as "nothing," as "impossible." Therefore, it lives in a different "world." The Lacanian subject and its world react with horror and abjection to any indication of such an existence, let alone to the idea that it might solidify what it sees into something like "knowledge." Within that space those who look back at this world's subject cannot articulate what they see. To this world, they cannot make themselves understood. Were the lake to betray any "knowledge" of its function, were it to break the surface of the mirror it is and tell the mountain that it is looking back at it, the bells on the cloud rack would turn into a death knell (glas).

By way of a solution Bachmann's poems often present themselves as unattributed yet self-conscious scenarios. They map a set of relations without breaking the mirror and assigning positions on this map to anybody. They do not claim to represent any objects other than those that volunteer to identify themselves. Bachmann's writing never "expresses" her. But it maps the arrangement which is responsible for her inability to express herself in the one world. Her texts maintain their difference from the epistemological procedures that engender the overbearing outline of the Western literary and philosophical canon. Thus, they help us recognize its silhouette. They help us see how Jacques Derrida, despite his reputation as a rebel figure, defined by his "difference" from the forces of the literary and philosophical tradition, returns into the fold of the one world.

${ }^{3}$ Mladen Dolar, " 'I Shall Be with You on Your Wedding-Night': Lacan and the Uncanny," October 58 (1991): 13, 20. 
Because Bachmann's texts thus fail to "contain" or speak what they "know," it is not enough to read them. The second half of her work is the different look at what it is not. Because a reading of Bachmann takes the strange form of a rereading of, for example, Nietzche or Derrida, it is also no longer simply "her" work. We have to sign for it ourselves. The difficulty of finding a format for such a doubly focused reading continues to beset my own work as a comparatist-feminist. As I reread and write about Derrida, Nietzsche, and Kafka, colleagues and deans remind me that I should be writing the promised "book on Bachmann." What they do not see is that both are part of the same project.

Ever since I began reading Derrida's work, I have felt the need to understand more precisely what appears to me a constitutive reliance of deconstruction on a very gender-specific placement in the intertextual network. That the subject of deconstruction is a male subject has been perceived in general terms, but just what this masculinity consists of remains to be understood. ${ }^{4}$

In this reading of "The Double Session," I approach the gendered site of the subject by focusing on Derrida's performance as a reader (rather than a writer). Two other performers make their way into that text through quotations of texts by Mallarmé (which in turn reach back into an extended textual prehistory). One of them is the ballerina from Mallarmé's "Crayonné au théâtre," who appears in the second part of Derrida's article only to disappear again promptly to make room for a discussion of the "blank" of generalized textual play. The other is the mime from "Mimique," in the same collection, on whose multiple performance Derrida overwhelmingly focuses. The proliferation of discourse around the mime and the ballerina's rapid disappearance signal a choice by which Derrida's discourse situates itself. ${ }^{5}$

What interests me are the discursive configurations that arise around these male and female figures, for they betray certain readerly allegiances which are inflected by gender. These allegiances are neither the expression of an essence nor a mere construction. In them, rather, a dynamic and complex practice takes shape which is responsive to and part of the structure of a signifying space that is thoroughly gendered.

"Barbara Johnson, for example, calls for analysis of gender issues in Derrida's work, but ambiguously invokes potential "epistemological damage" that might result from attempting to produce "the existence and knowledge of the female subject." See her essay "Gender Theory and the Yale School," in A World of Difference (Baltimore: Johns Hopkins University Press, 1987), 40-41.

${ }^{5}$ By contrast, Gayatri Spivak's interest in the functioning of the woman-sign leads her to single out the figure of the ballerina in her critique of Derrida, "Love Me, Love My Ombre, Elle," Diacritics 14.4 (Winter 1984): 19-36. 
It is significant that the mime is allowed to supply a scenario for the whole project of deconstruction, whereas Derrida self-consciously "arrests" the ballerina's play to turn her figure into a signifier. She becomes the site of inscription for his "knowledge."

Here I concentrate on Derrida's discussion of the male performerwriter figure of the mime and of Mallarmé's strategies in "Mimique." "Mimique" alludes to yet another text, a booklet by and about the mime Paul Margueritte, titled Pierrot Murderer of His Wife. In the plot, which persists through these allusions and repetitions, Pierrot, enraged by the infidelity of his wife, decides to tickle her to death. The drama is performed by the mime Margueritte alone: he plays the roles of both murderer and victim, and then writes and publishes a book about his performance. This story paradigmatically allegorizes the murder and exclusion of the "faithless" feminine subject in the history of Western representation. That this could have gone unremarked (until recently noted by Leslie Rabine) is an astonishing token of the reigning blindness to issues of gender in deconstructive discourse. ${ }^{6}$

Margueritte's booklet, object of explicit allusion by Mallarmé, does not close the play of intertextual reference, but rather opens it onto a series of countless precursor versions of the plot whose origin is lost in an extended network of repetitions and replays (DS, 198-205). The complex cross-references, mutual reflections, allusions, and inversions through which the mime's story plays with itself and its parts, the syntactic ambiguites of Mallarmé's text, and finally the relation between the performer-writer and his text all converge in the first part of Derrida's "Double Session" to represent the systematic unmasterability and undecidability of textuality which so fascinates deconstructive discourse.

But there is an element of stability in Derrida's reading: Mallarmé's text remains firmly framed by the reference to Plato's logocentrism. Derrida's reading shuttles between establishing the difference between Mallarmé's practice and logocentrism, and suspending that difference in allusion, referral, and return. Thus, the reading establishes the "veil" of an "undecidable" relation between Mallarmé's text and the founding text of Western metaphysics. This "veil" both does and does not perform a break with that past and its procedures. The break folds right back into that from which it would break, and it generalizes its own movement: "This redoubling of the mark, which is at once a formal

'Leslie Wahl Rabine: "The Unhappy Hymen between Feminism and Deconstruction," in The "Other" Perspective in Gender and Culture: Rewriting Women and the Symbolic, ed. Juliet Flower MacCannell (New York: Columbia University Press, 1990). 
break and a formal generalization, is exemplified by the text of Mallarmé, and singularly by the "sheet' you have before your eyes" (DS, 193-94). Repetition and generalization expand this suspension of difference into "nothing other than the space of writing" (DS, 208): the one (and to Derridean deconstruction only) world. The cohesion of this world depends on the break which generalizes it without departing from it and on the "sheet before your eyes" that prevents reading.

Anticipating the suspicion that such continued self-referentiality of a whole tradition might be considered an act of closure, Derrida insists that "such is not the case. A writing that refers back only to itself carries us at the same time, indefinitely and systematically, to some other writing. ... [The] structure is open and closed at the same time" (DS, 202). But that "other writing" is also "writing," and thus more of the same. What is denied both existence and "knowledge" is not "other writing" but anything other than or exterior to this writing. The hymen "eliminates the exteriority or anteriority, the independence of the imitated, the signified, or the thing" (DS, 210). We are meant to read this "elimination," of course, in the spirit of a resistance to a metaphysics of originary presence which would evade the complexities of language and textuality. Yet this constant turn back to the logocentric paper tiger is as oppressive and confining as logocentrism itself. It colonizes and recontains the space of potential difference. If logocentrism centers on one self-identical presence, deconstruction admits only one difference: the suspended "veil" between itself and logocentrism.

The continuities and discontinuities that create this veil, however, are open to rearrangement. And precisely because "absolute" difference is impossible, we must choose our (dis)continuities carefully. A place where the continuity between the text of metaphysics and that of deconstruction is particularly strong, however, is in the rhetorical function of gender. And in this place I would obviously prefer to introduce discontinuity.

In the pantomime about the Pierrot who tickled his wife to death, the mime plays both gender roles at once, while declaring them indistinguishable and "suspending" their difference. "The crime, the orgasm, is mimed doubly: the mime plays the roles of both Pierrot and Columbine alternately... such that in the final analysis what happens is nothing, no violence, no stigmata, no traces; the perfect crime in that it can be confused only with the heights of pleasure [jouissance] obtainable from a certain speculation" (DS, 201). But this performance is double in a very limited sense, since there is only a single performer: the white-faced male. Any other performance, including that of Columbine, remains offstage and hors-texte. Its very possibility is thus outlawed by 
the summary dismissal of any exteriority to the space of writing quoted earlier. The trace of the "crime," therefore, consists in this very absence.

But what if one chose to supplement Derrida's text with this "missing" performance? Like Bachmann's "lake," this perspective allows us to discover what it is we are "forbidden to know": that the "nothingness" of the hors-texte is also not absolute but perspectival. It is the blind spot that founds the play of writing.

In view of this elimination of otherness by the one world, one must reassess the significance of the two-directional traffic between the double text and its single performer which the story of the mime comes to represent. "Among diverse possibilities, let us take this: The mime does not read his role; he is also read by it. Or at least he is both read and reading, written and writing, between the two, in the suspense of the hymen, at once screen and mirror" (DS, 224). We can now no longer regard this scenario of "undecidability" as implying in any way a loss of control for the mime or his readers. Rather, from the vantage point of an absent Columbine-mime who gets to mime no role at all, the backand-forth between the mime and his two roles presents a scenario that illustrates his control over signification. The performer can participate in writing the script, and the writer can adjust the performance. As long as the mime is read by a scenario that confirms this arrangement, his "subjection" to reading amounts to his acknowledgment (in the Hegelian sense of Anerkennung) by the textual tradition. Text and performance fold into each other, occur in terms of each other, in a selfreinforcing loop which creates a protective antre/cave/womb. A difference greater than that "between Platonism and itself, Hegelianism and itself" (DS, 207), and thus between the history of male subjectivity and itself, is not allowed to interrupt this circuit.

The mime's scenario, then, illustrates not the elusiveness of a general textual play, but the control over representation and self-representation afforded by the privilege of an undecidable relation between a text and its proper reader. This control is secured by the stable specular exchange between a particular subject and its knowledge, but it also remains confined to the protective space of this "writing."

To mark the fertile juncture where difference is both established and contained, Derrida turns to the metaphorics of the "hymen":

To repeat: the hymen, the confusion between the present and the nonpresent, along with all the indifferences it entails within the whole series of opposites ... produces the effect of a medium (a medium as element enveloping both terms at once; a medium located between the two terms). It is an operation that both sows confusion between opposites and stands 
between the opposites "at once." . . But this medium of the entre has nothing to do with a center. (DS, 212)

The hymen becomes both divide and envelope, both the mark of difference and the space or union that recuperates it. With this wedding/ veil, the deconstructive reversal has produced its own, dissimulated version of a "center."

"Within" that space this play still necessitates the "nothing" that marks the absence of any greater difference. A state of "identity" which lost that trace may be a logocentric subject's chief desire, but it would have disastrous consequences. Were the mime's exchangeability with himself to lose that "nothing" which separates him from himself and enables him to play with himself, he would be incapacitated. The dilemma of a subject deprived of this split or symbolic "castration" is nicely evoked in an epilogue to one of Harold Bloom's books:

At midnight he went down to the lake, to hear the name spoken over the water, but found no one there to meet him.

So he became two, one to speak the name and one to receive it.

He forgot which one was which.

Both spoke the name, and neither received it.

Then both stood to hear it, but it was not spoken. ${ }^{7}$

"Speech" and "identity" here represent not the plenitude of the speaking subject's masterly self-presence, but rather his predicament in the absence of writing: he cannot mark difference.

This is why the name of woman, the role of Columbine, must remain inscribed in the plot. Her name is necessary for the mime to remember "which is which" when he says "I am I." It allows him to distinguish between the two roles he plays undecidably as a "subject" in control of self and representation. But he must perform both roles himself to produce "one" subject in the end. Thus the claim of that other name ("woman" or Columbine) to a referent different from, once more, him is denied. Her name becomes the mere mark of suspended (and thus neutralized) difference, the veil itself, and "nothing" beyond.

In the protective space of generalized writing thrives a decentered subject which no longer explicitly insists on its universality. On the contrary: it claims to have disappeared at the precise moment when its "universalization" within that space completes itself, since there is no longer anybody else in sight. The combination of the presence of "wom-

7 "The Name Spoken over the Water," in Harold Bloom, Kabbalah and Criticism (New York: Continuum, 1984), 127. 
an's" name and the "nothingness" of its referent facilitates the consummation of Narcissus' marriage to the infinite refractions of himself, separating him from and reuniting him with himself:

\begin{abstract}
"Hymen" ... is first of all a sign of fusion, the consummation of a marriage, the identification of two beings, the confusion between two. Between the two, there is no longer difference but identity. Within this fusion, there is no longer any distance between desire ... and the fulfillment of presence, between distance and non-distance; there is no longer any difference between desire and satisfaction. It is not only the difference ... that is abolished, but also the difference between difference and non-difference.... By the same token ... there is no longer any textual difference between the image and the thing, the empty signifier and the full signified, the imitator and the imitated, etc... The confusion or consummation of this hymen eliminates the spatial heterogeneity of the two poles in the "supreme spasm," the moment of dying laughing. (DS, 209)
\end{abstract}

The logocentric male subject has thus been replaced by the writing subject. Unlike his predecessor, this undecidable performer of his own text no longer bases his "identity" on his difference from "woman." She is dismissed together with the illusion of his substantial selfidentity and replaced by the more flexible trace of a gender difference, a veil that spells either difference or union according to need. In the double scene of departure and return, each actor can substitute for the other-Husserl for Hegel for Plato, Derrida for Nietzsche for Mallarmé for Margueritte - as they enjoy the ethereal pleasures of an infinite play with their like(nesse)s. The white noise of a self-supplementing tradition sets the stage for itself, performs itself on it, and watches the play, too. These, however, are the benefits of hegemony, not the unsettling effects of a general absence of reference.

Nevertheless, Derrida expends much energy on the impossibility of tracing any origin in the incessant cross-referencing of Western metaphysics. "One could go on at great length in order to find out where this Pierrot had read the exemplary story of this husband who tickled his wife and thus made her laughingly give up her life. With all the threads provided by the commedia dell' arte, one would find oneself caught in an interminable network" (DS, 205). Yes, but one would be engaged in a pointless search. The "origin" is not the problem. The point is not whether Plato, Derrida, or anybody else has "authored" the pernicious mechanism, but rather that this history consists of endless repetitions of the same tired old story. The effort at change must address itself not to a phantasmatic origin but to the exact form taken by, the choices made in, repetition and mimesis. 
By situating our reading in the trace left by Columbine's absence, we catch sight of a would-be murderer who theorizes his ability to escape conviction in front of an infinite series of self-portraits or mirrors which mime his movements as he mimes theirs. Like so many Ancient Mariners, they obsessively replay that old story. But the murder is strangely pointless, since its victim is said not even to exist. A clue to this bizarre spectacle may be Derrida's remark that the "difficulty lies in conceiving that what is imitated could be still to come with respect to what imitates, that the image can precede the model, that the double can come before the simple" (DS, 190). If what is imitated is still to come, the mime can never know whether he will have succeeded or not. The future and the elided alterity converge in the "nothing" as which they appear to him, and as which they reside irreducibly in his suspended difference from himself. He is trying to convince himself that we who approach this text now from the angle of this nothing are either dead or not there. But he knows that this is not true, and so do we. He cannot be convicted, then, because the murder fails. The unsuccessful "deed" is therefore replaced by the unceasing repetition of this story. And yetas long as we participate in this repetition and take his representations for "truth," we will indeed be as good as dead.

Since we are not dead, however, his privilege to represent himself in the world and to reserve the right to appear onstage becomes uncomfortable. He begins to look for ways to transcend his specular captivity in representation. He wishes that he, too, were invisible, a mere nothing, a "blank." 8 The mime's desire to extend his play "infinitely" through the "one world" of writing coincides with the desire to disappear from view. If he succeeds in being that world, he becomes invisible.

I argued earlier that the deconstructive reversal does not undo the cohesion produced by the "center," but rather preserves it in a dissimulated version. The logocentric effacement of representation in the name of presence now similarly fails to be undone. The subject of deconstruction, consonant with its desire not to be seen, has developed its own version of effacement. No longer is the trace of representation effaced on behalf of an image of presence, meaning, or the subject. Now, inversely, the undecidable play of textuality is generalized and becomes an imperative emanating from the text as the "image" in which the subject is to be fashioned:

What Mallarmé read, then, in this little book is a prescription that effaces itself through its very existence, the order given to the Mime to imitate noth-

${ }^{8}$ The "blank" has a completely different meaning for the ballerina. This point I study in greater detail in the unpublished second half of this article. 
ing that in any way preexists his operation.... It is prescribed ... to the Mime that he not let anything be prescribed to him but his own writing, that he not reproduce by imitation any action ... or any speech.... The Mime ought only to write himself on the white page he is. (DS, 198)

The reader-performer now lives under the imperative to be nothing but a spontaneous repetition of his own writing. A "self-effacing" text is complemented by a reader-performer striving to assimilate himself to an omnipresent and purportedly untraceable self-recursivity without origin, conceived in the image of the text, imitating nothing but itself.

The relation between text and mime is "undecidable." What is not "undecidable," however, is the very specific "meta-mimetic" interaction that binds this textual space and its mime. The readerly activity of the mime produces the undecidability and brings about the selfrecursivity of this kind of writing, and finally effaces the mime's role in doing so. Not any particular image, but the self-recursivity of writing itself which he thus creates becomes the image in which he models himself. (What this means concretely will become clearer in the next section.) The symbiotic interaction between the space of writing and the specific subject which thrives in and on it, finally, is dissimulated by a generalization that declares this interaction an impersonal and aperspectival process.

Let us have a closer look at the "blankness" of the self-effacing textand-mime. Derrida rightly points out that the blank is not simply a theme. "The 'blank' and the 'fold' cannot in fact be mastered as themes or as meanings, if it is within the folds and the blankness of a certain hymen that the very textuality of the text is re-marked" (DS, 245-46). No "theme" can be stably represented because every representation is incomplete without the supplement of a reading that re-marks and confirms it. The unsignifiable signification of the blank is that every signifier (including itself) can always be made to mean something different: "The blank or the whiteness (is) the totality, however infinite, of the polysemic series, plus the carefully spaced-out splitting of the whole... But for the reasons just enumerated, it is out of the question that we should erect such a representative ... into the fundamental signified or signifier in the series" (DS, 252). This "signification" cannot be confined to one signifier without disappearing.

The substitutions must be performed as one subject or meaning is displaced by the next in an open series. The "erasure" that occurs there is a change in what is read, not an unreadability. And "unreadability" inversely is a reading. Strictly speaking, there is thus no "blank" at all except as a theme. The "blank" appears only if we totalize and represent this process of substitution in general. Unreadable is only the "totality" 
of those transformations, and the only gaze blinded by this unreadability is the very particular gaze of the old universal subject. Whenever this blindness turns into a privileged "knowledge" which overarches and adjudicates all "local" attempts to read, that universal subject reasserts its hegemony in the space of reading. This strategy as a whole manifests what Nietzsche critiques as the "ascetic" desire rather to "will nothingness than not will." ${ }^{\prime}$ It wills unreadability rather than allow somebody else to read.

When this new subject-in-general is subject to reading, a complementary gesture occurs: the mime wears the simulacrum of a blank on his face. "The blank - the other face of this double session here declares its white color-extends between the candid virginity... of the white... page and the white paint of the pale Pierrot who, by simulacrum, writes in the paste of his own make-up, upon the page he is" (DS, 195). The mime is trying to convince us that he has already erased or "deconstructed" himself, and that we therefore do not have to go to the trouble anymore. He has already returned to the innocence of the white page. Like animal mimicry, the "blank" he wears on/as his face betrays an attempt to blend into an environment and become invisible to potential predators. The white paint, however, is indeed only a simulacrum of nothingness. It betrays his desire to be invisible rather than fulfilling it.

The mime has moved to a stage on which his erasure is imperativethe scene of reading. What he has not left behind are his old signifying habits. He behaves as though erasure could be written, painted, signified. If the "blank" is a representable theme after all, erasure is not. His deeper dilemma is that he cannot erase himself. This is the one thing out of his control. He can only continue to write and to multiply traces which become readable as the effort of the "universal subject" to retain control of the point of his own demise.

What cannot be written are the changing practices and repetitions which representations encounter and undergo. Let me therefore conclude with a look at two citations in Derrida's and Bachmann's works, and at the specific turns they take as repetitions. Here, too, the two writers make opposite and complementary choices.

The first citation occurs in one of Derrida's footnotes to "White Mythology." He quotes a text by André Breton, upon which he has, however, "neither the time nor the place to comment":

There is no doubt that I have a "complex" about ties. I detest this incomprehensible ornament of masculine costume. From time to time I reproach

${ }^{9}$ Friedrich Nietzsche, On the Genealogy of Morals, trans. Walter Kaufmann and R. J. Hollingdale (New York: Vintage, 1969), 163. 
myself for surrendering to such an impoverished custom as knotting each morning before a mirror (I am trying to explain to psychoanalysts) a piece of cloth which by means of an attentive little nothing is to augment the already idiotic expression of a morning jacket [veston à revers]. Quite simply, it is disconcerting. I am not unaware, from another point of view, and indeed cannot hide from myself, that just as coin operated machines, the sisters of the dynamometer on which Jarry's Supermale practices victoriously ("Come, Madame"), symbolize sexually-the disappearance of the tokens in the slot-and metonymically - the part for the whole-woman, so the tie, and even if only according to Freud, figures the penis "not only because (they) are long dependent objects and peculiar to men, but also because they can be chosen according to taste, a liberty which in the case of the object symbolized, is forbidden by nature."10

This passage falls into two parts, between which there occurs a shift in perspective. In the first part an " $\mathrm{I}$ " augments the veston à revers (the "turncoat" by means of which he is able to switch sides) by an "attentive little nothing" which remains, however, "incomprehensible." In the second part he "cannot hide" from himself "another perspective." There he recognizes the tie he finds himself wearing as a mark of masculinity. The whole monologue addresses itself to "psychoanalysts." Psychoanalysis is meant to close the gap of the attentive nothing of reading with the presence of an analyst who, as we know, functions like a white wall, interpreting nothing, only handing every utterance back to the speaker for interpretation.

Although Derrida does not comment, he does tell us what he sees. Gazing at this text, Derrida sees a "page from the Vases communicants on which Breton analyzes an ornament, attending to the rhetorical equivalents of condensation and displacement, and to their economy." He sees both the "page" and a man who analyzes its rhetorical displacements, and whom he recognizes as "Breton." Derrida thus vacates his place in front of the mirror of the text in favor of Breton. He folds the text back onto itself without comment as the analyst who comes to Breton's rescue and cures his "loss." Effacing his readerly presence, he restitutes Breton to himself as his own destination, his own gaze out of the mirror, and produces the self-recursivity of an authorial subject "in" the text. Now, the space of writerly subjecthood is surrounded by "white walls" which merely fold it back onto itself, "eliminating" every hors-texte. But this "folding back" does not happen by itself. It is a

${ }^{10}$ Jacques Derrida, "White Mythology: Metaphor in the Text of Philosophy," in Margins of Philosophy, trans. Alan Bass (Chicago: University of Chicago Press, 1982), 222. The quotation in Breton's text is from Freud's "Interpretation of Dreams." 
specific readerly supplementation of writing which buttresses the space of male authorship. Derrida himself causes the shortage of a "time" or "place" from which to comment on this space.

This is a miniature model of the stance of deconstruction: it colonizes the open space of reading by returning it to (the subject as) writing. It shrinks the time and space of reading. Thus, the writing subject averts his deconstruction by replacing the self-conscious moment when " $\mathrm{I}$ " looks in the mirror with the psychoanalyst's folding back of an unread text. But there is a price to be paid for this strategy: a subject constructed in this way can no longer be "self-conscious" or read at all. "Pierrot returns, and is summoned to testify to his own death: 'I can rejoice no longer in seeing myself"' (DS, 204). ${ }^{11}$ This subject rewrites himself as an undecidable play between "blanks." Reading is now a white wall, the text a blank page, and the mime's face white makeup. For fear of encountering the object $a$, his eyes go blank.

In this rewriting a blanket authorial "attentiveness" is installed, masterfully and "omnisciently" presiding over a text that has turned into a mere "page." Text and reader avoid committing themselves to any "content" beyond the specificity of this arrangement. If we grant him this blanko awareness of anything that goes on in "his" text, any displacement will have been attended to by the Author Himself. By reading Breton in this way, Derrida "writes himself on the page which he is." But "Himself" can no longer look the " $\mathrm{I}$ " in the eye.

As I read this way, however, I repeat Derrida's move. I "see" Derrida reading, when in fact, right now, I myself am doing the reading. Therefore, the question to me as a reader is: Do I, since I clearly have a complex about certain incomprehensible ornaments of masculine costume, want to surrender to the impoverished custom of knotting in front of a mirror? And if I do not want to read so as to reestablish "Himself," what are my other choices?

In my view, Ingeborg Bachmann offers an alternative in "The Writing I" ("Das schreibende Ich"), the third of her five "Frankfurt Lectures on Poetics." 12 There she quotes a passage from the novel The Unnamable by Samuel Beckett. She, too, does not "comment" on what she quotes, but merely frames it with a small remark. In Beckett, she writes, there

\footnotetext{
${ }^{11}$ Compare also the atypical modesty with which Nietzsche notes that "the unpleasant thing, and one that nags at my modesty, is that at root every name in history is I." Friedrich Nietzsche to Jakob Burckhardt, January 5, 1889, quoted in Rosalind Krauss, "Bachelors," October 52 (Spring 1990): 53-59.

${ }^{12} \mathrm{~A}$ translation of these lectures into English is being prepared by Karen Achberger and will appear in a series titled "Kritik: German Literary Theory and Cultural Studies," edited by Liliane Weissberg and published by Wayne State University Press.
} 
finally occurs the liquidation of content altogether ("Bei Beckett endlich kommt es zur Liquidation der Inhalte überhaupt" (IBW, 4:235):

And man, the lectures they gave me on men, before they even began trying to assimilate me to him! What I speak of, what I speak with, all comes from them. It's all the same to me, but it's no good, there's no end to it. It's of me now I must speak, even if I have to do it with their language, it will be a start, a step towards silence and the end of madness, the madness of having to speak and not being able to, except of things that don't concern me, that don't count, that I don't believe, that they have crammed me full of to prevent me from saying who I am, where I am, and from doing what I have to do in the only way that can put an end to it, from doing what I have to do. How they must hate me! Ah a nice state they have me in, but still I'm not their creature, not quite, not yet. To testify to them, until I 'die, as if there was any dying with that tomfoolery, that's what they've sworn they'll bring me to. Not to be able to open my mouth without proclaiming them, and our fellowship, that's what they imagine they'll have me reduced to. It's a poor trick that consists in ramming a set of words down your gullet on the principle that you can't bring them up without being branded as belonging to their breed. But I'll fix their gibberish for them. I never understood a word of it in any case, not a word of the stories it spews, like gobbets in a vomit. My inability to absorb, my genius for forgetting, are more than they reckoned with. Dear incomprehension, it's thanks to you I'll be myself, in the end. Nothing will remain of all the lies they have glutted me with. And I'll be myself at last, as a starveling belches his odourless wind, before the bliss of coma. ${ }^{13}$

Does this magnificent act of citation need any comment? Bachmann makes this text speak for her more strongly than it could ever have spoken for Beckett because nothing of what it says is the "content" of the text. No author "attended to" this displacement. It happens only as and in the repetition of the text in reading. It is therefore only if we, too, read it this way that this citation performs what could not be written without being lost, and what the mimes with the white faces try hard and in vain to simulate in order to prevent it: the usurpation of the speaker's image in the mirror as our reverse gaze takes over the eye/"I." Rather than folding reading back into writing, we thus fold writing out into reading.

There is a hint of a system of justice and judgment in the word citation, which goes together with the hesitation on the part of writers

${ }^{13}$ Molloy, Malone Dies, The Unnamable: Three Novels by Samuel Beckett, trans. Patrick Bowles (New York: Grove Press, 1965), 324-25. Bachmann quotes, of course, a German translation (see IBW, 4:235-36). 
such as Breton and Derrida to "commit themselves." Derrida abandons the search for a determinate content, but as we have seen, he ends up walling in the space of writing and committing himself to it as a whole-and so do those who follow him. Nobody who ends up thus imprisoned can plead innocence for their confinement. Nor can those, man or woman, who find themselves inconvenienced by a tie around their neck: "Pierrot's death in Algiers is being announced by Harlequin ('Bah! nothing's surer: his obituary, / On the opening pages of each dictionary, / Is visibly written with paraphs profuse, / Just under a Pierrot attached to a noose')" (DS, 204).

The specific direction taken by my work as a comparatist and a feminist derives from my desire to avoid either of two fates. I do not want to continue "knotting before the mirror" and assimilate myself to "man" and his text by serving as his blind analyst/double. I have nothing to gain from such assimilation, and everything to lose through it. Nor will I commit suicide by responding to murderous interpellations like those of Breton's slot machines. I have to be careful to read, therefore, neither "as a man" nor "as a woman," but as that which both is "lost" in representation and remains "yet to come." I have to look in the mirror of representation and recognize myself not as whatever "face" I see there but exclusively as that which is not represented: the gaze which is, always at this very moment, looking. This gaze cannot be preserved in any representation. But it also cannot be prevented by representation. And without it, without us, all those books would remain inert. This repositioning allows for a reevaluation of the centurylong chase for the "object," the "referent," the "truth" from the perspective of that which continued to escape in this process. What thus got away is our life.

Bachmann's may be one of the most carefully theorized works in the consistency with which it maintains this perspective. But it is certainly not alone on the far side of the writerly space of the white-faced mime and his old story. One of the tasks I see for myself is therefore to continue to read for the "large trace" of the kind of difference I have tried to map here. Works such as Bachmann's will remain unreadable in their difference unless we develop new critical strategies and very different readerly skills capable of following the subtler traces of the work done by writers who write without "representing" themselves. Their difference can appear only if we learn to see with different eyes, and to go quickly from one light into another, the compass point in the heart. 